Climatic Change, Volume 90, Numbers 1-2, pp 169-187, September 2008.

\title{
Preliminary evaluation of the benefits of a participatory regional integrated
} assessment software

\author{
I.P. Holman ${ }^{I_{\varpi}}$, J. Harman ${ }^{2}$ \\ ${ }^{1}$ Natural Resources Department, School of Applied Sciences, Cranfield University, UK \\ ${ }^{2}$ United Kingdom Climate Impacts Programme (UKCIP), Oxford, UK
}

Corresponding author: I.P. Holman

Natural Resources Department

Cranfield University

Cranfield

Bedford MK43 0ALT

United Kingdom

Tel: $\quad+44(0) 1234750111$

Fax: $\quad+44(0) 1234752970$

Email: i.holman@cranfield.ac.uk

\begin{abstract}
This paper provides a preliminary evaluation of the Regional Impact Simulator - a user-friendly, PCbased tool designed with stakeholders for stakeholders wishing to assess the effects of climate and/or socio-economic change on the important sectors and resources in the UK at a regional scale, in particular, impacts to coastal and river flooding, agriculture, water resources and biodiversity. While
\end{abstract}


integrated assessments are relatively new, simulators that help stakeholders visualize and think about potential changes in the environment or society at a regional scale are very new. An earlier project, RegIS1, was the first local/regional integrated assessment conducted in the UK. It developed a method for engaging stakeholders in a "stakeholder-led" integrated assessment process. The RegIS2 project developed a simulation tool and followed the same "stakeholder-led" principle in designing and testing the tool. The role of stakeholders in informing the design of the simulator is discussed here, as is a stakeholder evaluation survey on its success in meeting its objectives. We also reflect on the need and desire of stakeholders to have such a tool. And because the Steering Committee - made up of stakeholders - was so invaluable in ensuring the usefulness of research outputs, a series of Steering Committee 'rules' is proposed intending to maximise the benefits of this valuable resource. Finally, we outline how our experience with the 'Regional Impact Simulator' serves as a test-bed for further studies of stakeholder-led, regional, integrated assessment.

\section{Introduction}

Expected changes in climate (e.g. Hulme et al., 2002) due to anthropogenic greenhouse gases emissions (IPCC 2007) is likely to affect all sectors of society at all scales, ranging from the global to the local. However, these impacts will be in addition to, or concurrent with, continuing socioeconomic and political changes (IPCC, 2007; Nakicenovic and Swart, 2000). Climate change impacts on our changing future therefore need to be evaluated holistically, from multiple perspectives. "Integrated assessment" (IA) has been defined by the Intergovernmental Panel on Climate Change as "an interdisciplinary process that combines, interprets, and communicates knowledge from diverse scientific disciplines from the natural and social sciences to investigate and understand causal relationships within and between complicated systems" (IPCC, 2001).

There are two main principles to integrated assessment if it is to enable decision making: (1) integrate over a range of relevant disciplines and sectors, and (2) provide new information about how complex 
real-world systems might behave. As many stakeholders have the responsibility for decisions implementing climate change adaptation policy at the local or regional (sub-national) level, (Shackley and Deanwood 2002), DETR (2000, p 138), it is the capacity to synthesize a broad range of information suited for understanding climate impacts at the regional scale that is greatly needed, a view supported by Dessai and Hulme (2004), Turnpenny et al. (2004) and Dempsey and Fisher (2005). It follows therefore that there is a real need for tools that support decision making and policy development at this scale.

The UK Climate Impacts Programme (UKCIP) was established by the UK Government in 1997, with the aim of providing a research framework for the integrated assessment of climate change impacts in the UK. UKCIP works with stakeholders to co-ordinate research on how climate change might impact at regional and national scales and how stakeholders might adapt to these impacts. To manage expectations, set achievable and acceptable goals and ensure that needs are met, we are seeing that decision making processes on the whole and integrated assessments in particular are broadening the scope of multiple perspectives to include the perspectives of stakeholders. UKCIP, for example, directly involves stakeholders in the research. It is the stakeholders or their partners who commission the research and determine the research agenda. UKCIP provides support and guidance throughout the process; it provides a bridge between stakeholders, researchers and decision-makers in government organisations and business.

UKCIP supports a range of stakeholder-led and funded studies and partnerships on climate change impacts and adaptation. Studies examining local-scale vulnerability to climate change have been undertaken in all regions of England, as well as the Devolved Administrations of Scotland and Wales, to encourage organisations within these areas to take notice of the need for climate change adaptation. Additional sectoral studies have been conducted that address climate change impacts and adaptation at a national level. 
The structure and mission of UKCIP were developed through a scoping exercise (SPA and ESYS, 1996). This scoping exercise also suggested that pilot climate impact assessments should include both natural system integrated assessments of climate-induced water changes and their impacts on other sectors, as well as a regional integrated assessment on upland land use. These ideas led to the 'Regional Climate Change Impact and Response Studies in East Anglia and North West England,' or RegIS1, (Holman et al., 2005 a \& b) which was conducted under the umbrella of UKCIP from 19992001. It assessed local and regional climate change impacts and adaptation options, and cross-sectoral interactions between four major sectors driving landscape change (agriculture, biodiversity, coasts and floodplains, and water resources). RegIS1 was the first regional integrated assessment (IA) in the UK and piloted a stakeholder-led approach.

In a supporting facilitative role, UKCIP has developed a 'standardised' framework for climate impact and adaptation research and provides tools to support decision making and policy development at a national-level. Tools include climate scenarios (Hulme et al., 2002), national socio-economic scenarios (UKCIP, 2001a), a decision-making framework for adaptation (Willows and Connell, 2003) and a costing methodology (Metroeconomica 2004).

However, 'what-if' tools, tools that help us think into the future and think about the later consequences of our choices today were lacking. RegIS1 did not have a 'what if' tool, but demonstrated the need for stakeholders to be able to 'see' potential cross-sectoral impacts and synthesize information from diverse sources. It highlighted that the complexity of information and the complexity of the models we use to organize it hindered the broad participation of the stakeholder community. The subsequent RegIS2 project (Holman and de Vries, 2005) is a response to this. Its aim was - adhering to the stakeholder-led approach of RegIS1 - to deliver a heuristic tool (Figure 1) that stakeholders could install on their own PC's and use unsupported, as and when required. The resulting Regional Impact Simulator (Holman et al., 2008) is the first simulation tool developed for stakeholders by stakeholders provided on the UKCIP website (www.ukcip.org.uk). 
RegIS1 $=\quad$ Regional Climate Change Impact and Response Studies in East Anglia and North West England

RegIS2 $=\quad$ Follow-on project to RegIS1, which developed the Regional Impact Simulator

Being only the second integrated assessment of the UK at the regional level, this paper considers how the stakeholder-led RegIS2 project has moved IA forward and provides a preliminary evaluation of the tool's success from the perspective of the user community. Scientific insights gained from the tool are the focus of the paper by Mokrech et al. (2008), Audsley et al. (2008), Henriques et al. (2008), Harrison et al. (2008) and Richards et al. (2008).

\section{The ending of RegIS1 and beginning of RegIS2}

Upon completion of RegIS1 (Holman et al., 2005 a \& b) in June 2001, UKCIP hosted an end-ofproject workshop to reflect on the project, and discuss its results and how to further improve integrated assessments within UKCIP. The workshop was attended by around forty participants, including representatives from the RegIS1 steering committee and research teams, as well as researchers, stakeholders and funders from around the UK. Participants were asked specifically to reflect on:

- the use/ usefulness of the assessment results to stakeholders;

- issues concerning uncertainty

- the user-friendliness of the results;

- outstanding questions that require further research; and

- recommendations for improving future integrated assessments

From a conceptual point of view the stakeholder-led approach within RegIS1 made sense, but did it produce better outcomes? This end-of-project workshop enabled stakeholders to reflect on scientific insights gained about climate change impacts and adaptations at a regional scale, as well as on the stakeholder-led approach. Inevitably for RegIS1 - the first such project of its kind - the workshop produced a large number of recommendations (UKCIP, 2001b) for improving future assessments, 
including requests for modelling techniques that simplify the complexity, so called 'metamodels' or 'reduced form models' (Carmichael et al.. 2004). So the RegIS2 project set out to develop these modelling approaches within the simulation tool, as well as further the stakeholder-led approach to integrated assessment. The proceeding discussion of the RegIS2 project focuses on the simulation tool within the context of the views expressed by stakeholder and funder at the post-RegIS1 workshop outlined in UKCIP (2001b). In particular this paper seeks to assess:

1. the success of the Regional Impact Simulator in meeting its objectives and in addressing the needs of stakeholders;

2. the potential contribution of the Regional Impact Simulator to stakeholder decision-making and learning;

3. the management of the researcher / stakeholder interface within stakeholder-led projects;

4. the lessons learnt about participatory integrated assessment;

5. the developments needed for regional integrated assessments in the UK.

\section{Stakeholder evaluation of the Regional Impact Simulator}

The design and development of the Regional Impact Simulator is described fully in Holman et al., (2008). Of paramount importance, however, was to ensure that the simulator could be used by nonscience experts (Kasemir et al., 2000; Hanson et al., 2006). Therefore, an interface that was as intuitive as possible was built around the user and usability requirements (Pahl, 2004), not the science. The participatory design approach (Dittrich and Lindeberg, 2004) provided necessary input from stakeholders for interface development on their expectations and requirements (Welp, 2001; Hanson et al., 2006) and established (with the Steering Committee) mutually agreed-upon guiding concepts. The literature as well as experiences, from researchers, UKCIP and participating stakeholders alike, contributed to the guiding concepts described below:

Design - make it 'intuitive' to use and the outputs easy to understand

- The physical layout of the tool (where components are placed relative to others and how the operations are presented) should closely mirror the conceptual model used to 
think through the operations, i.e.; the Driver-Pressure-State-Impact-Response (or DPSIR) components (Holman et al., 2008);

- The slider bars, used to vary input parameters, should be numerically labelled and convey assumptions of the model/scenario (Schneider, 1997);

- 'Realistic' and plausible ranges of values for a given parameter should be used to give guidance on the uncertainty associated with a scenario (Turnpenny et al.. 2004);

- Allow the user to concurrently view and compare graphical output from more than one model or scenario (Olsson and Andersson, 2007);

- Appeal to a broad range of users, users with different priorities or values, by enabling progressively detailed exploration of the topics (Dempsey and Fisher, 2005);

Speed - prevent users from 'switching off'

○ Avoid extensive or prolonged model set-up;

○ Provide outputs rapidly;

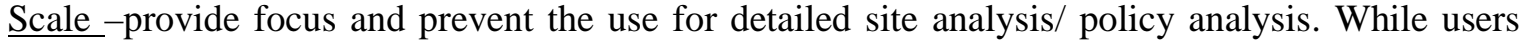
should be encouraged to study the detailed maps, this output is not suitable for detailed site analysis, nor should it be confused with the policies that would accomplish those outcomes.

○ Present principal outputs at a regional scale (aggregated).

- Allow the user to vary input parameters to 'see' the potential regional changes (Response)

With these initial guiding concepts and a rough implementation sketch (see Holman et al., 2008, and the pre-study stage of Dittrich and Lindeberg, 2004) a series of prototypes were developed to plot the evolution of user requirements and functionalities. The interface evolved to three screens, each with a different purpose and increasing levels of interaction with the model variables, which are described fully in Holman et al. (2008). The screens now provide an ordered hierarchy of user interaction and, importantly, the DPSIR approach to thinking about change:

- The Predefined Scenario Futures screen allows the user to rapidly become familiar with indicators and their sensitivity to the different climate and socio-economic 
scenarios. The default set of input parameter values for each scenario allows a rapid model set-up.

- The Exploratory Analysis screen allows the user to explore a scenario in greater detail, by changing the input parameter values used in the models. This enables the user to explore the effects of the widely acknowledged uncertainty in any scenario, which cannot be defined by a single set of unique values.

$\circ$ The Influencing the Impacts screen allows the user to test regional adaptation responses to the impacts identified with the Exploratory Analysis screen. The screen shows the regional scale outcomes of changes (Response) rather than the policies that would accomplish those outcomes, because the tool is not intended for intervention in specific policy analysis.

\subsection{How successful was Regional Impact Simulator in meeting its objectives and in delivering the needs of stakeholders?}

The question of what is meant by the utility of a model for stakeholders is extensively debated in the literature (e.g. Shackley. 1998). Merton (1957) first made the distinction between the 'manifest' and 'latent' function of models, where the manifest function (does the model provide robust answers?) is the one that appears to be the legitimate explanation of the model's utility in decision-making. However, not infrequently there is also a latent function (Does the model provide consensus and agreement on the legitimacy of a course of action?) which lies 'beneath the surface' (Shackley and Gough, 2002). However, Olsson and Andersson (2007) state that important conditions for the successful use of models as communication tools with stakeholders are credible results, user relevance, user friendliness and transparency.

From a scientific perspective, RegIS2 was successful in developing computationally simpler modelling techniques for integrated assessments, which produce credible results and have provided new understandings (Mokrech et al., 2008; Henriques et al., 2008; Audsley et al., 2008; Harrison et al., 
2008; Richards et al., 2008). The question asked here, however, is whether the user-friendly interface was successful. Whether the stakeholder community will use the Regional Impact Simulator and the RegIS methodology is of paramount interest but this question cannot be answered yet. Simply providing credible, quality information and tools are not enough to ensure that decision makers and stakeholders will used them (Dempsey and Fisher 2005). We will only be able to address this latter question now that the Regional Impact Simulator is freely available to the wider stakeholder community through the UK Climate Impacts Programme website (www.ukcip.org.uk) and time to use it has elapsed.

To provide a preliminary assessment of interface usability, a prototype of the Regional Impact Simulator was made available to a group of approximately 60 volunteer stakeholders for external evaluation. These stakeholders were affiliated with national Government (8), regional Government (5), local Government (6), NGO's (18, ranging from National Park authorities and environmental regulators to sustainability fora), charities (5), commercial organizations (11, ranging from water and power utilities to consultancies) and academic/research institutions (6). They came from within the two study regions, from elsewhere in the UK and from outside the UK.

The evaluation process was intended to provide preliminary independent feedback on the design and functionality of the Regional Impact Simulator, rather than on the numerical values of the output itself. Although users were obviously expected to install and run the tool on their won PC's, they were specifically not being asked to say if, for example, the value of the river flow exceeded $95 \%$ of the time in catchment $\mathrm{X}$ was correct or not- the technical evaluation of the models is described elsewhere in the Special Issue, in earlier papers (e.g. Holman et al., 2005b; Rounsevell et al., 2003; Pearson et al., 2002) and technical reports (Holman and Loveland, 2001, Holman and de Vries, 2005). Questions addressed the design and operation of the interface, the usefulness of the model outputs and potential future developments (see Appendix). Users were asked to score their answers between 1 (low) and 5 (high) or to identify strengths and weaknesses. Eleven individuals returned evaluation forms. Their feedback provided a useful provisional metric for determining whether the Regional Impact Simulator 
achieved its aims. Non-responders were also followed up, of which 17 provided explanations -9 were too busy to carry out the evaluation within the given time period, 2 felt that the software wasn't relevant, and 8 had IT difficulties. The latter mostly related to getting the software certified as safe and installed on centrally-controlled networked systems, suggesting that such problems may represent a considerable constraint on both stakeholder participation in similar studies and stakeholder uptake of tools. Although not included in the quantitative evaluation exercise, positive verbal feedback has been received following demonstrations of the tool at seven stakeholder meetings and conferences within the UK.

The key metrics of success for the interface of the simulator were:

1. Was it deemed easy to use and intuitive by users?

2. Were runtimes considered acceptable by users?

3. Were the outputs useful to the users (therefore, were the indicators appropriate)?

\subsubsection{Ease of use and intuitiveness of the Interface}

All bar one of the respondents rated the ease of use/intuitiveness of the Interface as adequate or better than adequate, although none rated it 'very easy' (with an average score from all respondents of 3.5). There was an approximately even distribution of responses to how long it took to understand how to use the Regional Impact Simulator. There was no relationship found between how long it took them to figure out how to use the simulator and whether they felt the design was intuitive. About half used the help tutorial and half did not (5 used the tutorial while 6 did not). All those who required more than an hour to understand the interface used the help tutorial, as did some who required half an hour or less.

It is not possible to meet the diverse needs of all stakeholders with one design. Nevertheless, all respondents did report satisfaction with the simulator, encouragement and at least partial affirmation for the hierarchical three-screen layout and design.

\subsubsection{Satisfaction with the model run-time}


During the initial design of the Regional Impact Simulator, a target run-time of 1 second was set. The final run time of 10-20 seconds is longer than this. This was due in part to the finer spatial resolution adopted by the flooding metamodel $\left(1 \mathrm{~km}^{2}\right.$ grid $)$ and partly to the reading and writing of files between the many metamodels. The runtime has also been shown (in Holman et al. 2008) to be computerdependent. Nevertheless, all but 2 of the respondents rated the runtime as adequate or better than adequate (average score of 3.2). The least satisfied respondent replied that the 'maximum admissible' runtime was 5 seconds. Although a 'typical' new PC results in a runtime of less than 20 seconds ( in Holman et al. 2008), it can be reduced to around 10 seconds when the biodiversity models are excluded - the last in the cascade of metamodels.

\subsubsection{Appropriateness of the results}

The hands-off nature of the evaluation exercise, with stakeholders installing and running the software on their own PC's, meant that they were free to reflect on the 'usefulness' of the tool and its indicators within the context and remit of their own responsibilities without any possibility of implicit coercion on the part of the research team or funder, which might arise during a mediated session. While aiming to appeal to a broad range of moderately technically-minded users, the Regional Impact Simulator cannot produce outputs suitable for all purposes. All users were interested in different specifications, spatial boundaries and, in some case, already employed their own standard methodologies. A generic tool such as the Regional Impact Simulator cannot hope to meet all expectations and needs. Nevertheless, the evaluation of the usefulness of the Indicators and results were generally positive, with all respondents rating both the usefulness of the indicators (average score of 3.8) and model results (average score of 3.5) as adequate or better than adequate. Despite the differing spatial boundaries of the participating organizations, the value of the outputs could be seen. However, in reality it is likely that providing a tool which does not correspond to the boundaries of an organization's remit will limit its usefulness, which is partly reflected in the stakeholder feedback on further developments (Section 7). 
A simulator able to meet all requirements would require customized versions linked to rather specific plans, policies or strategies (Demeritt and Langdon 2004) and the ability to incorporate local knowledge useful for interpreting and relating the results 'on the ground'. The extensive range of stakeholder needs would preclude customized versions for everyone. Yet for some the case could be argued that the investment of time and testing with practitioner stakeholders is well worth trying.

Overall, comments received following the evaluation suggest that users recognise the potential for the outputs of the Regional Impact Simulator to support a range of their activities:

"We believe that [the Regional Impacts Simulator] has a huge potential to raise awareness of the implications of policy decisions, and therefore guide policy and decision makers down a more sustainable track"

"Overall we believe it is a useful tool to demonstrate the linkages and impacts"

"It's very encouraging to see the potential solutions for many items that are put into the 'too difficult' box."

“tool provides a valuable (essential) advocative medium to embed need for adaptation and underpin cross sectoral policy development/decision making"

"I fully support the concept behind RegIS [the Regional Impacts Simulator]".

\section{The potential contribution of the Regional Impact Simulator to stakeholder decision-making}

\section{and learning}

The Regional Impact Simulator was intended to contribute to stakeholder decision-making and learning by, in the first place, allowing users to visualise the impacts of climate and socio-economic change. It is anticipated that the Regional Impact Simulator helps improve stakeholders' understanding of climate and socio-economic impacts through visual illustrations on maps and with graphs of how climate and socio-economic scenarios might affect different sectors. Secondly, it allows users to explore the drivers of change and their potential impacts to the landscape and to four areas of human activity (and decision making) and thereby give a better sense of plausible adaptation options and potential consequential effects. Finally, because there are multiple interactions between 
the sectors driving landscape change, a tool to help stakeholders understand cross-sectoral issues and explore different perspectives of the same issue is expected to be useful to them in exploring uncertain futures and consequently the implications of their possible decisions in the broader context - a regional context.

The uncertainties that are associated with a climate change impact assessment are difficult to work with. However, the Regional Impact Simulator makes this task a bit easier by giving reasonable boundaries to uncertainty. "Slider bars" (Figure 2) define the range of 'reasonable' uncertainty for a given indicator. (The 'reasonable range' is based on expert advice.) The user can then experiment with the slider bar to examine the sensitivities of the system within a reasonable range of uncertainty. A traffic light-based system of colour coding the slider bars was used to differentiate between "credible" uncertainty (green, for 'go') and more "extreme" uncertainty (yellow, for 'caution'), possible, but somewhat outside conventional wisdom. For obvious reasons, a user is not permitted to enter the 'red' zone, beyond the range of plausibility. The ability to explore uncertainty with the Simulator is expected to be very useful to decision-makers, especially when considering which adaptation options are most viable.

UKCIP encourages stakeholders and decision-makers to use a range of its tools to identify how they might be impacted by climate change and what they can do to adapt. The Regional Impact Simulator is a tool to create and assess management alternatives, and it integrates two tools provided by UKCIP already, the UKCIP02 climate change scenarios (Hulme et al., 2002) and the socio-economic scenarios (UKCIP, 2001a; Shackley and Deanwood, 2003), thus maximizing on the affect of familiarity with the subject matter and, therefore, the effort invested on behalf of the user. In fact prior to the Simulator, stakeholders had difficulty understanding and using the socio-economic scenarios. Within the Simulator, however, it appears that much of the difficulty of understanding how to use socio-economic scenarios disappears. It is anticipated the simulator should result in greater use of socio-economic scenarios in decision-making and planning. 
Additionally, the different levels of analysis allowed by the Regional Impact Simulator (Figure 2-4) fit well with other climate impact assessment tools provided by UKCIP. The Risk, Uncertainty and Decision-Making Framework (Willows and Connell, 2003) allows for analyses to be undertaken at varying levels of detail. The Simulator can be used within the Risk, Uncertainty and Decision-Making Framework to either quickly determine major impacts they should consider, or perform a very detailed sensitivity analysis of the uncertainties and adaptation options.

The Simulator was developed to enable both 'top-down' and 'bottom-up' approaches to assessment. The first two screens (see Figure 3: Pre-defined Scenario Futures and Figure 2: Exploratory Analysis) fulfil a prediction-oriented 'top-down' approach - from global scenarios to impact models. Whereas the 'bottom-up' approach which focuses on stakeholder expertise in interpreting the adaptation options is delivered with the third screen (see Figure 4: Influencing the Impacts).

In considering the use of the Regional Impact Simulator within adaptation frameworks, a broad distinction can be made between its use in informing the implementation of adaptation decisions and in building adaptive capacity. Implementing adaptation decisions focuses on avoiding or reducing the cumulative impacts of climate change, ensuring that distributional impacts of adaptation are minimised and ensuring that adaptive measures taken by one organization or sector do not adversely impact upon others (Adger et al., 2005). While the Regional Impact Simulator can inform many decisions, through spatially displaying the impacts and consequences of regional adaptation responses, two key areas stand to benefit significantly from this tool. They are in:

1. informing the integration of adaptation actions and policies across sectors, ensuring that adaptation resulting from actions in one sector does not reduce the effectiveness of purposeful adaptation in another sector. According to Adger et al., (2005), this remains a key challenge in achieving successful adaptation;

2. searching for robust adaptation strategies (Lempert and Schlesinger, 2001) that are scenarioindependent (Dessai and Hulme, 2004) or no-regret, low-regret or win-win strategies (Willows and Connell, 2003) i.e.; adaptation responses which will be beneficial (or at worst 
not detrimental) for all possible future socio-economic development pathways (Lempert and Schlesinger, 2000).

Building adaptive capacity increases the ability of individuals, groups or organizations to adapt (Adger et $a, ., 2005)$ and includes communicating climate change information and building awareness of potential impacts at an appropriate regional level. Decision support tools, such as the Regional Impact Simulator, are tools for analysis and vehicles for communication, training, forecasting and experimentation (Welp, 2001). The Regional Impact Simulator will therefore contribute to the UK Governments objective of a well adapted UK by building the capacity of UK decision-makers to understand the climate and socio-economic impacts and how these might be reduced by various adaptation options. The Regional Impact Simulator will hopefully result in regional scale decisionmaking and policy formulation which takes due account of the impacts of climate change.

\section{Lessons learnt on managing stakeholder-led projects}

An axiomatic principle of stakeholder-led research is that the research results should be useful to stakeholders. However, to achieve this desired outcome there are a number of challenging or conflicting priorities which have to be managed during the course of any such project. Who are the stakeholders? What do they actually want? What can realistically be delivered (within the limits of funding, time and knowledge)? In climate impacts research, the cross-cutting nature of many issues means that these are potentially of interest to a range of stakeholder groups, such that their breadth of interests and priorities are potentially overwhelming, if not conflicting.

Fundamental to addressing these questions and helping deliver the appropriate outputs of stakeholderled research is a Steering Committee that includes stakeholder representatives. It will depend on individual project (and funder) circumstances as to who is responsible for setting up the Steering Committee - the research group or the funding organization(s). Individual project circumstances will also determine of the range of stakeholders represented - from national to local scale organizations, 
trade bodies to conservation NGO's, government departments to agencies, etc. The 10-person Steering Committee of RegIS2 was set up by the research team to have broad representation (note: an organization or its representatives may represent more than one category). Represented were:

$\underline{\text { National and regional government- }}$

- $\quad$ national: Department for Environment, Food and Rural Affairs- Defra

- $\quad$ regional: Government Office for the East of England- GO-East

National and regional responsibility-

- $\quad$ national: Defra, UKCIP, UK Water Industry Research- UKWIR, English Nature

- regional: GO-East, Environment Agency- Thames and North West region representatives)

$\underline{\text { Sectors- }}$

- $\quad$ agriculture: Defra

- $\quad$ water resources: Environment Agency and UKWIR

- $\quad$ water supply: UK Water Industry Research

- $\quad$ flood management: Environment Agency

- $\quad$ conservation: Defra, English Nature and Environment Agency

Commercial interests- UK Water Industry Research

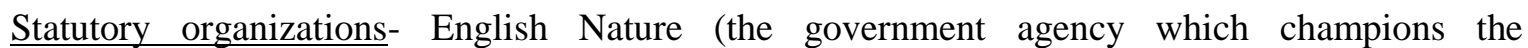
conservation of wildlife, geology and wild places in England) and the Environment Agency (the Competent Authority under the European Water Framework Directive)

External to the region: Environment Agency- Thames region representative, South East Climate Change Partnership and UKCIP

Policy focussed: Defra and Government Office for the East Of England

Technically focussed: all others 
Based upon the experiences gained through RegIS2 and other stakeholder-led research projects, it is also important to highlight several key guidelines for a Steering Committee within the research process:

- Members act as filters between the researchers and the stakeholder communities, translating diverse stakeholder desires into clear and consistent guidance as to the needs and priorities which the research team should aim towards;

- Members contribute advice and suggestions to the debate in order to increase the likelihood that research outputs are "useful" to stakeholders. There are no silent members in a Steering Committee. To avoid retrospective disagreements "silence is taken to mean agreement".

- Members contribute the experience and knowledge of their organizations to the deliberations, whether this be to the science, policy frameworks, adaptation responses etc. There is a danger that non-technical or non-climate change specialist stakeholders will view themselves as having nothing to contribute to a research project. ALL member have different, yet important, contributions.

- Priorities will vary across researchers and stakeholders and may need balancing, in particular, the needs of researchers to do cutting edge, publishable, research and the needs of stakeholders' to have pragmatic questions answered which may not require cutting edge research. Although less problematic in projects funded by stakeholder organizations (as in RegIS2), this problem can be particularly acute when research is jointly funded by stakeholder organizations and Research Councils, as research quality is the main criterion used by the latter to judge proposals, whereas utility is the main criterion of the former;

- Members will share (e.g., project models, outputs, methodologies etc) with their own organisations and networks to road-test and validate approaches.

- Representatives from organizations will be those who can inform model or methodological development, will use a project's outputs and can promote their use.

There is a final responsibility on both sides (Steering Committee and research team members) to be open to, listen to and understand each other's perspectives. With all of these conditions in place, the 
Steering Committee provides a win-win contribution - the Research Team is given a consistent and clear steer as to the direction and needs of the research, the Steering Committee members gain useful knowledge for their organization or sector, and the funders can demonstrate useful outputs at the end of the project.

\section{Lessons learnt for future participatory IA software development}

Software engineering texts (e.g. Pressman, 2005) describe software development as analogous to a waterfall having distinct consecutive phases of problem analysis, specification, design, implementation, testing and release. In the Regional Impact Simulator, not one but multiple models were being developed. So, the object-oriented approach was valuable in allowing software modularity, and therefore the ability for different research groups to iteratively develop their models autonomously, yet at the same time. However it must be said that the apparent initial success of the Regional Impact Simulator is in no small way due to the participatory approach. The interface development benefited greatly from the iterative prototyping process which was informed through the early identification of user needs and progressive researcher-stakeholder feedback, producing a final design that is both visually appealing and provides easy access to the necessary outputs (Dempsey and Fisher, 2005).

One premise underlying the development of the Regional Impact Simulator was that such a tool should be beneficial to a broad range of stakeholders. One major design issue was therefore how to accommodate a broad audience of end users with different needs. The solution was to provide two alternative interface screens, predefined scenarios and exploratory analysis, to accommodate users of different ability to interact effectively with the modelling framework. The predefined scenarios screen allows users with less knowledge of the nuances of scenario construction to still run the model (for a limited set of outcomes). The more advance user is able, through the exploratory analyses screen, to vary parameter values through on-screen sliders. Using this part of the system assumes some prior knowledge of how the individual sectors operate and interact, as well as some understanding of the limits and credibility of alternative scenarios. 
Clearly this tool may be used inappropriately, either inadvertently or deliberately to demonstrate a biased viewpoint, which was a significant concern of some Steering Committee members. Inappropriate use could manifest itself in two main ways:

- by setting variables unrealistically, which bear no resemblance to the underlying storyline behind a scenario;

- by combining, but not acknowledging, futures (scenarios) that are inconsistent with each other e.g. a high emissions climate scenario combined with a 'sustainability' socio-economic scenario - which erroneously suggests that the high economic activity behind the climate scenario is not so detrimental for the environment.

It is not possible to prevent inappropriate use without severely restricting the flexibility of the user to explore uncertain futures, which would rather defeat the object. So the interface was designed to highlight 'credible' ranges when setting the pressure variable of each model. In addition, when a setting is changed from the default setting, the title "User Defined" appears on the maps and graphs to indicate that the settings in use may not be consistent with the scenario selected. Alternatively, the transparency of the tool (Yearley, 1999) allows potentially biased viewpoints to be challenged, dissuading the inappropriate use of the tool. By making the tool available in the public domain and by revealing parameter settings and scenario combinations, each can then be independently verified.

\section{Future Developments}

Although RegIS2 was only the second regional IA project in the UK, it should not be automatically assumed that further research, model development etc is needed. The project evaluation (section 3.1) therefore asked whether or not stakeholders felt it would be useful to develop the Regional Impact Simulator further. All respondents supported further development (average score of 4.3) with most being highly positive (scoring 4 or 5 out of 5). To understand the desired direction of possible future developments, the evaluation then asked whether further development should be based on expanding 
or changing the range of sectors simulated within the tool; expanding or changing the regions modelled or extending the tool to provide national coverage. Although a small number of respondents felt that the scope of any further development should be determined by a further consultation exercise and therefore did not express a preference, most respondents selected different or additional regions (5 respondents) and national coverage (9 respondents). For example:

"..it is imperative that further support is given to this project, to help develop the product to be truly region, or nation, wide."

Two issues became evident from this element of the evaluation. Firstly, there is a demand for regional integrated assessment. Many of the respondents were in regional or national organizations and could see the benefits of such a tool for their own area. Secondly, despite a perception in favour of regional scale outputs, respondents felt that national coverage was also required for decision making with regard to climate change impacts and adaptation. This may reflect the small size of the UK and the importance of national institutions such as the regulatory organizations (e.g. Environment Agency, English Nature).

\section{Conclusions}

This article evaluates the participatory design approach to the development of a regional integrated assessment tool, the Regional Impact Simulator. The Regional Impact Simulator was designed to allow stakeholders to explore for themselves the potential consequences of future climate and socioeconomic change in two regions of England. As the first such tool designed for interactive - rather than assisted - stakeholder use in the UK, and perhaps Europe, both model and interface development were developed iteratively - and with on-going involvement and input from the people and organizations intended to use it. 
The two most significant applications of the Regional Impact Simulator are likely to be 1) to inform the integration of adaptation actions and policies across sectors, such that unintentional adaptation resulting from actions in one sector does not reduce the effectiveness of purposeful adaptation in another sector, and 2) to explore robust adaptation strategies which are scenario-independent or noregret strategies (i.e.; adaptation responses which will be beneficial for all future scenarios).

A preliminary independent stakeholder evaluation of the Regional Impact Simulator, prior to releasing the software to the public, indicates that users find that the software is sufficiently easy and intuitive to use, the runtimes are acceptable, the outputs are useful and the Simulator merits further development.

The advice and guidance of the project Steering Committee have provided an invaluable contribution to the development of the Regional Impact Simulator, and therefore a series of Steering Committee 'rules' are proposed to help future projects gain maximum value from this valuable resource. In particular, a Steering Committee is a filter between the researchers and the many diverse needs of stakeholder communities, in order to give clear and consistent guidance to the research team. Its members contribute the diverse experiences and knowledge of their organizations and ensure that research outputs are "useful". It has added value in that it involves people who will take such tools as the Simulator into organizations to use as well as promote their use.

\section{Acknowledgements}

The Regional Impact Simulator was developed as part of the RegIS2 project (project CC0362), which was funded by the Department for Environment, Food and Rural Affairs, with support from UK Water Industry Research (UKWIR). The advice and guidance of the Steering Committee members from the UK Climate Impacts Programme, UKWIR, English Nature, Environment Agency, Government Office for the East Of England, South East Climate Change Partnership, and Defra has provided invaluable assistance. The views expressed in this paper are those of the authors and do not necessarily represent the opinion of UKCIP. 


\section{Appendix- Evaluation questionnaire}

Evaluation questions relating to the Regional Impact Simulator

- How intuitive / easy to use did you find the Regional Impact Simulator? [1-5; $1=$ Not very; 3 $=$ Adequate; 5 = Very easy $]$

- How long did it take to understand how to use the Regional Impact Simulator? [1 hour+/ $1 / 2$ hour / 1/4 hour]

- Did you need to use the help tutorial or the worked example? [Yes / No]

- Were you happy with the length of time it took to run the models? $[1-5 ; 1=$ Not very; $3=$ Adequate; 5 = Very happy

- If you thought the models took too long to run, how long should they take?

- What features did you like about the Regional Impact Simulator?

- Are there any ways in which we could make it easier to use?

- What, if anything, did you dislike about the Regional Impact Simulator?

- What other features or functions would you like to have in the Regional Impact Simulator?

Evaluation questions relating to the modelling

- Which sectors were of interest to you? You may select more than one.[Flooding, Agriculture, Water, Biodiversity]

- How useful were the chosen indicators? [1-5; $1=$ Not very; $3=$ Adequate; $5=$ Very useful $]$

- How useful were the results of the model? [1-5; $1=$ Not very; $3=$ Adequate; $5=$ Very useful $]$

- What other indicators would you like to see?

Evaluation questions relating to further development

- Do you think it would be useful to develop the Regional Impact Simulator further? $[1-5 ; 1=$ Not very; $3=$ Perhaps; 5 = Very useful] 
- If you think further development would be useful would you like to see (You may tick more than one):

○ [More Sectors / Different sectors/ If so, which sectors?]

○ [More regions / Different regions / If so, which regions?]

$\circ \quad[$ National Coverage]

- Please expand on what you would like to be further developed. Or any other comments

\section{References}

Adger WN, Arnell NW, Tompkins EL (2005) Successful adaptation to climate change across scales. Global Environmental Change 15: 77-86

Audsley E, Pearn KR, Harrison PA, Berry PM (2008) The impact of future socio-economic and climate changes on agricultural land use and the wider environment in East Anglia and North West England using a metamodel system. Climatic Change 90(1-2), 57-88

Carmichael J, Tansey J, Robinson J (2004) An integrated assessment modelling tool. Global Environmental Change 14: 171-183

Demeritt D, Langdon D (2004) The UK Climate Change Programme and communication with local authorities. Global Environmental Change 14: 325-336

Dempsey R, Fisher A (2005) Consortium for Atlantic Regional Assessment: Information Tools for community adaptation to changes in climate and land use. Risk Analysis 25(6): 1495-1509

Dessai S, Hulme M (2004) Does climate adaptation policy need probabilities. Climate Policy 4: 107128

DETR (Department for Environment, Transport and the Regions) (2000) Climate change : the UK Programme. HMSO, London, 210pp

Dittrich Y, Lindeberg L (2004) How use-oriented development can take place. Information and Software Technology 46: 603-617 
Hanson CE, Palutikof JP, Dlugolecki A, Giannakopoulos C (2006) Bridging the gap between science and the stakeholder: the case of climate change research. Climate Research 31(1): 121-133

Harrison PA, Berry PM, Henriques C, Holman IP (2008) Impacts of socio-economic and climate change scenarios on wetlands: linking water resource and biodiversity meta-models. Climatic Change 90(1-2), 113-139

Henriques C, Holman IP, Audsley E, Pearn K (2008) An interactive multi-scale integrated assessment of future regional water availability for agricultural irrigation in East Anglia and North West England. Climatic Change 90(1-2), 89-111

Holman IP, Rounsevell MDA, Cojacaru G, Shackley S, McLachlan C, Audsley E, Berry PM, Fontaine C, Harrison PA, Henriques C, Mokrech M, Nicholls RJ, Pearn KR, Richards JA (2008) The concepts and development of a participatory regional integrated assessment tool. Climatic Change 90(1-2), 5-30

Holman I.P, de Vries TT (eds.) (2005) Development of a metamodel tool for regional integrated climate change management (RegIS2). Final Report for Project No. CC0362, Department for Environment, Food and Rural Affairs, London.

Holman IP, Loveland PJ (eds.) 2001 Regional Climate Change Impacts in East Anglia and the North West (the RegIS project). Final report of Project No. CC0337, Ministry for Agriculture, Fisheries and Food, London. (available from www.ukcip.org.uk).

Holman IP, Rounsevell MDA, Shackley S, Harrison PA, Nicholls RJ, Berry PM, Audsley E (2005a) A regional, multi-sectoral and integrated assessment of the impacts of climate and socioeconomic change in the UK: I Methodology. Climatic Change 71: 9-41

Holman IP, Nicholls RJ, Berry PM, Harrison PA, Audsley E, Shackley S, Rounsevell MDA (2005b) A regional, multi-sectoral and integrated assessment of the impacts of climate and socioeconomic change in the UK: II Results. Climatic Change 71: 43-73

Hulme M, Jenkins GJ, Lu X, Turnpenny JR, Mitchell TD, Jones RG, Lowe J, Murphy JM, Hassell D, Boorman P, McDonald R, Hill S (2002) Climate Change Scenarios for the United Kingdom: 
The UKCIP02 Scientific Report. Tyndall Centre for Climate Change Research, School of Environmental Sciences, University of East Anglia, Norwich, UK, 120 pp

IPCC (2007) Climate Change 2007: The Physical Scientific Basis. Contribution of Working Group I to the Fourth Assessment Report of the Intergovernment Panel on Climate Change. Cambridge University Press, New York, pp. 996

IPCC (2001) Technical Summary. Climate change 2001: Impacts, Adaptation, and Vulnerability. A Report of Working Group II of Intergovernmental Panel on Climate Change Cambridge University Press, New York, p. 1000

Kasemir B, Schibli D, Stoll S, Jaeger CC (2000) Involving citizens in climate and energy assessments. Environment 42(3): 32-42

Lempert RJ, Schlesinger ME (2000) Robust strategies for abating climate change. Climatic Change 45: $387-401$

Lempert RJ, Schlesinger ME (2001) Climate change strategy needs to be robust. Nature 412: 543-545 Merton R (1957) Manifest and Latent Functions in Social Theory and Social Structure. Free Press, Glencoe, Illinois

Metroeconomica (2004) Costing the impacts of climate change in the UK: overview of guidelines. UKCIP Technical Report. UKCIP, Oxford

Mokrech M, Nicholls RJ, Richards JA, Henriques C, Holman IP, Shackley S (2008) Regional impact assessment of flooding under future climate and socio-economic scenarios for East Anglia and North West England. Climatic Change 90(1-2), 31-55

Nakicenovic N, Swart R (eds.) (2000) Special Report on Emissions Scenarios. A Special report of Working Group III of the Intergovernmental Panel on Climate Change. Intergovernmental Panel on Climate Change, Cambridge University Press Cambridge, p. 599

Olsson JA, Andersson L (2007) Possibilities and problems with the use of models as a communication tool in water resource management. Water Resources Management 21(1): 97110 
Pahl C (2004). Adaptive development and maintenance of user-centric software systems. Information and Software Technology 46: 973-986

Pearson RG, Dawson TP, Berry PM, Harrison PA (2002) SPECIES: A spatial valuation of climate impact on the envelope of species. Ecological Modelling 154(3): 289-300.

Pressman RS (2005) Software engineering: a practitioner's approach. McGraw-Hill, Boston

Richards JA, Mokrech M, Berry PM, Nicholls RJ (2008) Regional assessment of climate change impacts on coastal and fluvial ecosystems and the scope for adaptation. Climatic Change 90(12), 141-167

Rounsevell MDA, Annetts JE, Audsley E, Mayr T, Reginster I (2003) Modelling the spatial distribution of agricultural land use at the regional scale. Agriculture, Ecosystems and Environment 95(2-3): 465-479

Science and Policy Associates Inc and ESYS (1996) Proposal for a UK Integrated Climate Change Impacts Assessment. Report prepared for the Department of the Environment and the Environment Agency. Department of the Environment, London, p. 28

Schneider SH (1997) Integrated assessment modelling of global climate change: transparent rationale tool for policy making or opaque screen hiding value-laden assumptions? Environmental Modelling and Assessment 2: 229-248

Shackley S (1998) Introduction to Special Section on the Use of Models in Appraisal and PolicyMaking. Impact Assessment and Project Appraisal 16(2): 81-89.

Shackley S, Deanwood R (2002) Stakeholder perceptions of climate change impacts at the regional scale: Implications for the effectiveness of regional and local responses. Journal of Environmental Planning and Management 45(3): 381-402

Shackley S, Deanwood R (2003) Constructing social futures for climate-change impacts and response studies: building qualitative and quantitative scenarios with the participation of stakeholders. Climate Research 24(1): 71-90 
Shackley S, Gough C (2002) The Use of Integrated Assessment: An Institutional Analysis

Perspective. Tyndall Centre for Climate Change Research Working Paper 14. Tyndall Centre, Norwich.

Turnpenny J, Haxeltine A, O’Riordan T (2004) A scoping study of user needs for Integrated Assessment of climate change in the UK context: Part 1 of the development of an Interactive Integrated Assessment Process. Integrated Assessment 4(4): 283-300

UKCIP [UK Climate Impacts Programme] (2001a) Socio-economic scenarios for climate change impact assessment: a guide to their use in the UK Climate Impacts Programme. UKCIP, Oxford, p.123

UKCIP (2001b) Draft report of the RegIS Technical Workshop held at DEFRA, Nobel House, London on 26 June 2001. Unpublished UKCIP Report, Oxford, UK

Welp M (2001). The use of Decision Support Tools in participatory river basin management. Phys. Chem. Earth (B) 26(7-8): 535-539

Yearley S (1999). Computer models and the public's understand of science: a case study analysis. Soc Studies Sci 29(6): 845-866

Willows RI, Connell RK (eds.) (2003) Climate adaptation: risk, uncertainty and decisionmaking. UKCIP Technical Report, UKCIP, Oxford 


\section{Figure captions}

Figure 1 Schematic diagram of the structure and functioning of the Regional Impact Simulator

Figure 2 The second 'Exploratory Analysis' screen with slider bars, containing colour-coded uncertainty "bands", for changing input parameter values

Figure 3 The first 'Predefined scenario' screen for rapid visualization of impacts

Figure 4 The final 'Influencing the Impacts' screen for testing regional adaptation responses to identified impacts 


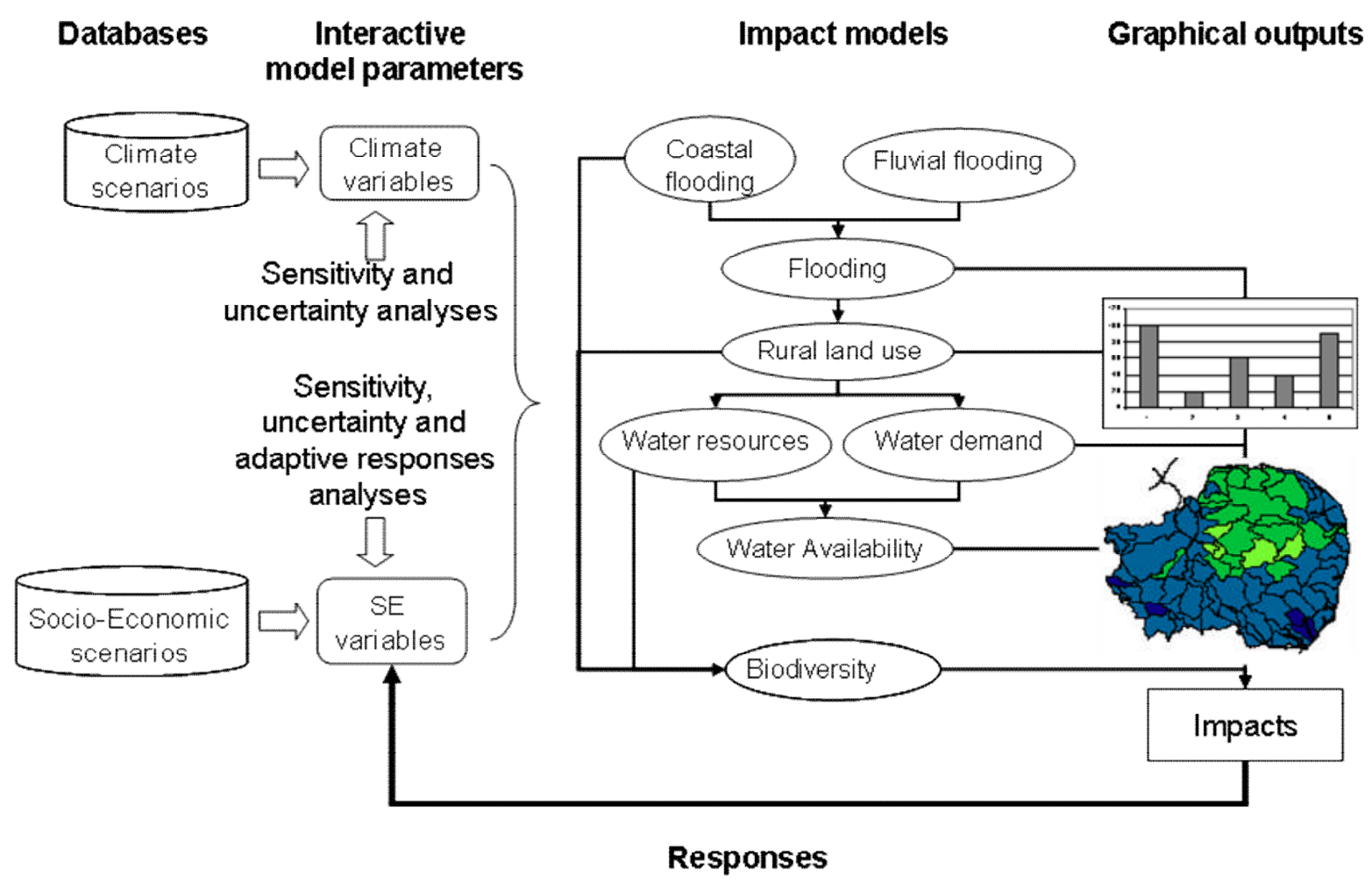

Figure 1 Schematic diagram of the structure and functioning of the Regional Impact Simulator 


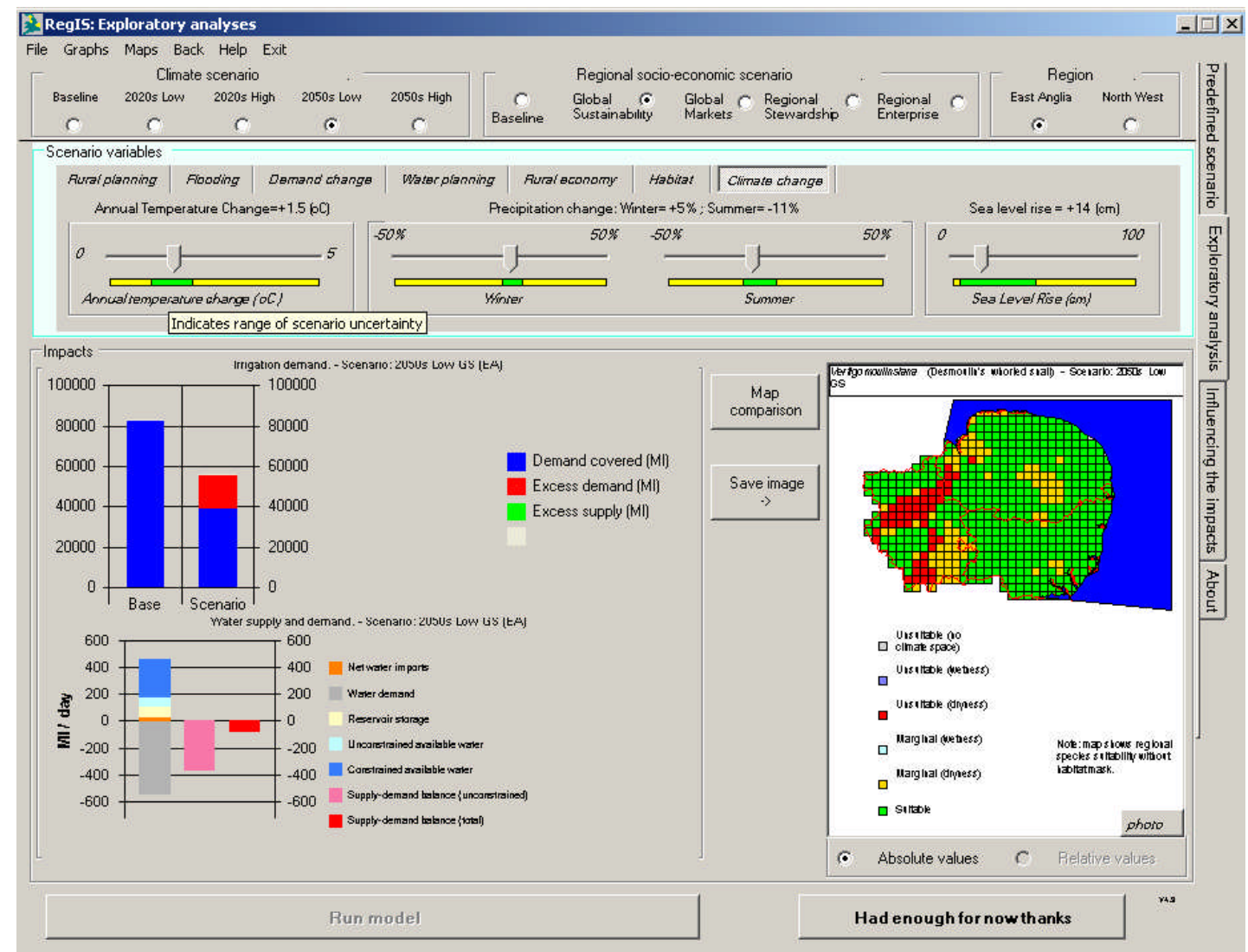

Figure 2 The second 'Exploratory Analysis' screen with slider bars, containing colour-coded uncertainty "bands", for changing input parameter values

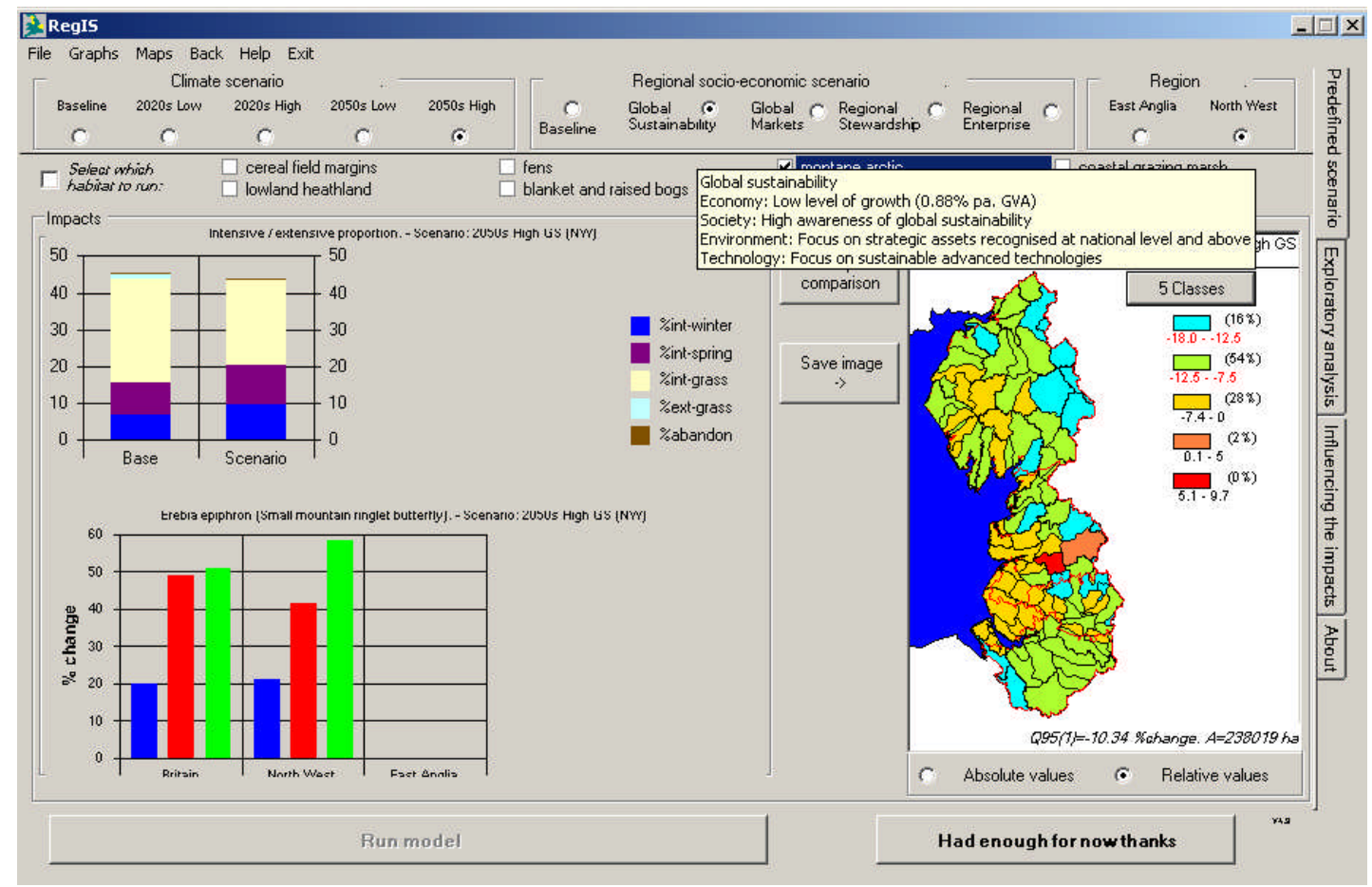


Figure 3 The first 'Predefined scenario' screen for rapid visualization of impacts

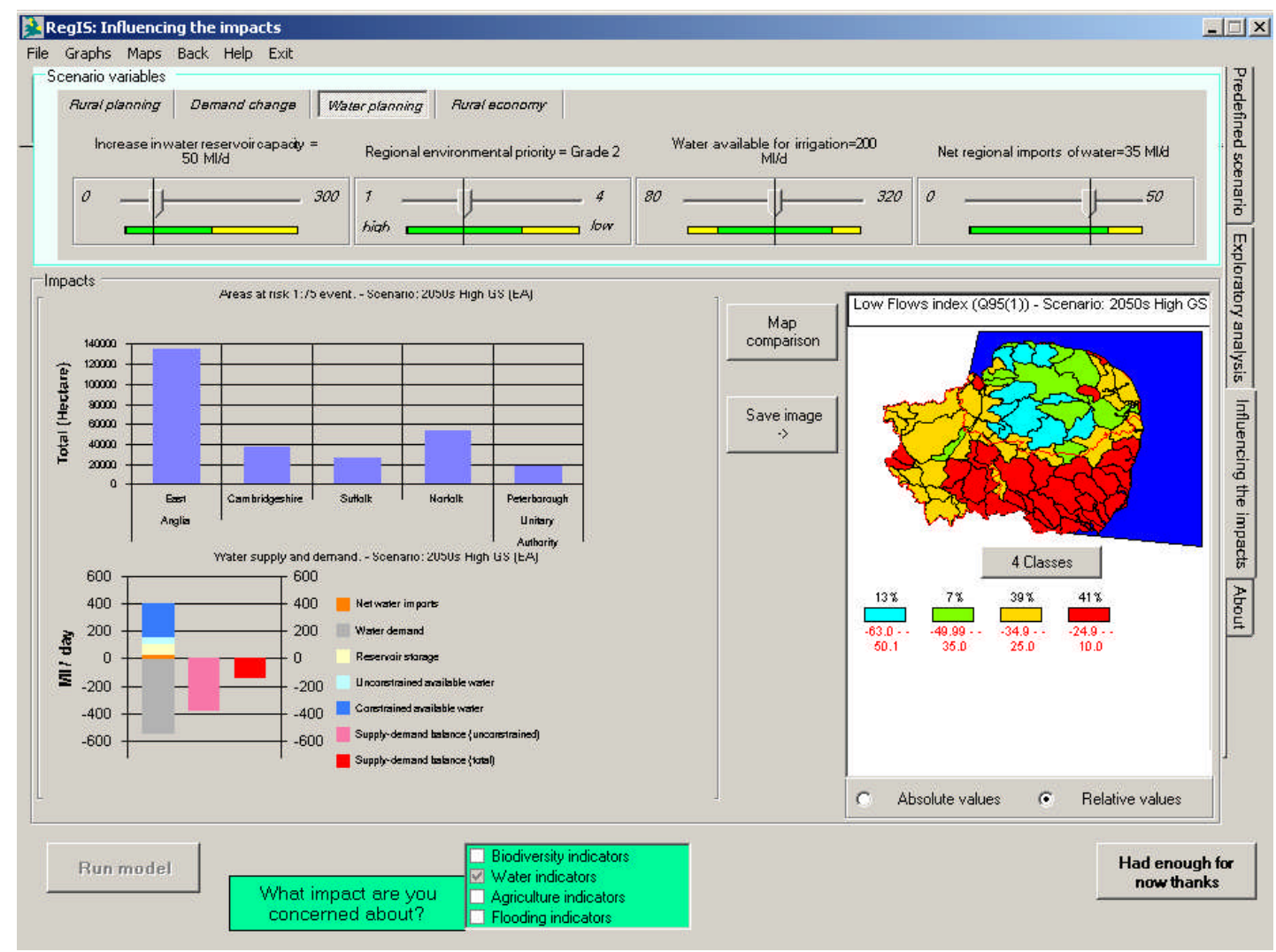

Figure 4 The final 'Influencing the Impacts' screen for testing regional adaptation responses to identified impacts 